\title{
Verification of External Thermal Insulation Systems with Composite Thermal Insulation and Different Renders in Effect of Hydrothermal Stress ${ }^{+}$
}

\author{
Rosita Norvaisiene ${ }^{1, *}$, Paweł Krause ${ }^{2}$, Vincent Buhagiar ${ }^{3}$, Arūnas Burlingis ${ }^{1}$ and \\ Kestutis Miskinis ${ }^{1}$ \\ 1 Institute of Architecture and Construction, Kaunas University of Technology, LT-44405 Kaunas, Lithuania; \\ arunas.burlingis@gmail.com (A.B.); kestutis.miskinis@ktu.lt (K.M.) \\ 2 Faculty of Civil Engineering, Silesian University of Technology, 44-100 Gliwice, Poland; \\ Pawel.Krause@polsl.pl \\ 3 Department of Environmental Design, Faculty for the Built Environment, University of Malta, \\ 2080 Msida, Malta; vincent.buhagiar@um.edu.mt \\ * Correspondence: rosita.norvaisiene@ktu.lt; Tel.: +370-603-00508 \\ + Presented at the 9th Innovations-Sustainability-Modernity-Openness Conference (ISMO'20), \\ Bialystok, Poland, 20-21 May 2020.
}

Published: 17 July 2020

\begin{abstract}
This paper is the research output of the laboratory ageing of external thermal insulation composite systems (ETICS). This was carried out in order to study the changes in properties of systems consisting of combustible and non-combustible thermal insulation materials, and four different types of finishing renders. Four types of the widely used, thin-layer facade rendering systems were subjected to hydrothermal cycles in a climate chamber in conformity with ETAG 004 guidelines. Analysis of the physical and mechanical properties (i.e., variation of temperature, water absorption, bond strength and mechanical resistance) of four types of ETICS are presented. This study indicates that there are no visible defects on any renderings over the junctions between polystyrene foam (EPS) and mineral wool (MW) materials when applied in ETICS.
\end{abstract}

Keywords: ETICS; rendering; thermal insulation; fire barriers; hydrothermal behavior

\section{Introduction}

One of the most effective methods to improve energy efficiency in new and renovated buildings is the use of insulation cladding applied directly on façades in the form of external thermal insulation composite systems (ETICS). The most important component ensuring a high performance of ETICS is their thermal insulation and limiting of heat losses through water penetration. Its effectiveness depends on its physical properties, method of attachment and connection with other system components [1-7]. Thermal insulation is attached to the wall with adhesive, together with additional mechanical fasteners. From the outside, it is covered with a reinforced fabric mesh with thin-layer plaster, exposed to the direct impact of changing weather conditions. Studies on the application of ETICS have demonstrated that the finishing coat is the most important because it is exposed to climatic variables and it is often the weakest coat of all the components of ETICS [8-11]. Precipitation, solar radiation and temperature differences may have a negative impact on the thermal insulation system, causing different types of damage [1,5-7,12-16].

Polystyrene foam (EPS) or mineral wool (MW) is the most commonly used facade insulation in Eastern Europe. Mineral wool is used in the case of performing a thermal insulation system on high buildings, in places where external walls are secured on the border of fire zones, or if there is significant moisture in the insulated wall. This often results in the need for two types of insulation, 
different in terms of physical properties, on the building's facade. In selected cases, there are irregularities in the connection of individual thermal insulation materials.

The dynamic development of construction technologies, together with the emerging new guidelines or recommendations, points to the need for practical verification of the adopted solutions. In order to prevent fast fire spread, different provisions can be made, including barriers of noncombustible material, such as mineral wool around the openings and horizontal isolation barriers around the buildings between different floors $[4,7,9]$. The idea behind this solution is to increase the fire safety of insulation systems using EPS. Parallel to the emergence of new recommendations, there are various technical doubts about the possible negative effects of such a combination. One of them is the supposition that there may be cracks in the reinforcing and plastering layers, due to different thermal expansions of materials under the influence of external factors, another possibility of discoloration on the facade, associated with different absorption rates of thermal insulation materials [6-8,16-18].

Despite the numerous research papers on the subject, practically no data can be found on the performance of ETICS with different thermal insulation layers during hydrothermal weathering. Therefore, analysis of the physical and mechanical properties (i.e., water absorption and mechanical resistance) of four kinds of ETICS is presented. The aim of this research work is to reproduce the hydrothermal behavior in laboratory conditions, in accordance with ETAG 004 [19], and assess the effect of different thermal insulation types on the whole hydrothermal behavior of ETICS.

\section{Materials and Testing Methods}

The rig for testing was made by use of the thermal insulation material EPS 70, $0.14 \mathrm{~m}$ width and mineral wool $0.14 \mathrm{~m}$ width as fire barriers. Laboratory tests were carried out in order to investigate the junctions of different thermal insulation materials. The subject of the study was an external silicate brick wall $3.0 \mathrm{~m}$ wide, $2.2 \mathrm{~m}$ high with two openings measuring $0.6 \times 0.4 \mathrm{~m}$ (Figure 1), prepared in accordance with 5.1.3.2.1 ETAG 004 [19].

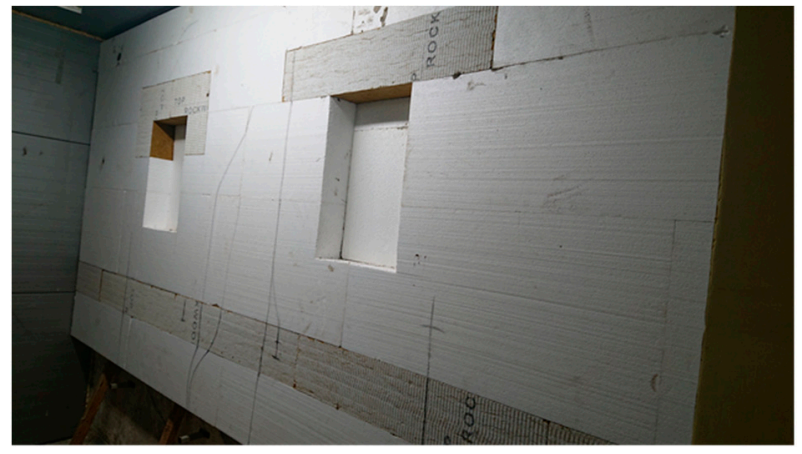

(a)

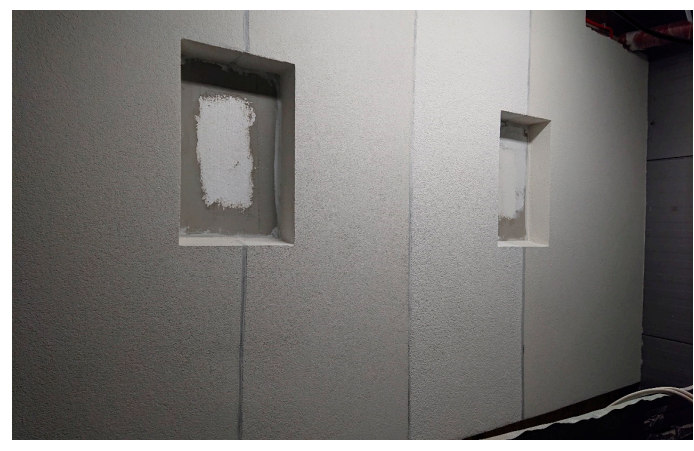

(b)

Figure 1. (a) EPS thermal insulation with mineral wool fire barriers; (b) test rig with 4 types of plastering.

In the lower part of the wall, a horizontal strip of $0.2 \mathrm{~m}$ width of mineral wool was inserted. Additionally, above the right opening, from the outside, another mineral wool strip, $0.2 \mathrm{~m}$ wide and $1.0 \mathrm{~m}$ long, was inlaid, and above the left opening a $0.2 \mathrm{~m}$ wide strip $1.0 \mathrm{~m}$, overlapping downwards at a distance of $0.2 \mathrm{~m}$. The entire wall was divided into 4 areas, with various types of plastering, i.e., acrylic (ETICS No. 1), silicate (ETICS No. 2), mineral (ETICS No. 3) and silicone (ETICS No. 4) (Figure 1b). Samples of ETICS were applied in accordance with the manufacturer's instructions on the test rig, which was subjected to 80 heat-rain cycles and to 5 heat-cold cycles, according ETAG 004 [19].

Temperature sensors were placed in selected characteristic points of the wall, with continuous data logging. They were located both within the connection of the supporting layer and the thermal insulation of EPS and mineral wool, as well as at the interface of both thermal insulation materials. After hydrothermal cycling, the specimens of insulation had been cut off the test rig and their humidity levels were determined. Following such tests, the hard body impact test according ETAG 
004 5.1.3.2.1 [19] was performed. In addition, the bond strength was determined according ETAG 004 5.1.4.1.1 [19] on the rig after ageing in order to analyze aspects of durability and serviceability. Square metal plates of $50 \mathrm{~mm}$ sides were affixed to three different areas of every ETICS (Figure 2): under the mineral wool insulation, EPS insulation and the junction between MW and EPS. The pull-off test was performed with a dynamometer (model CONTROLS C 215/D) with a manometer with a scale of 0 to $5 \mathrm{k} \mathrm{N}$ with resolution $50 \mathrm{~N}$. The mean failure resistance was based on the results of the five tests.

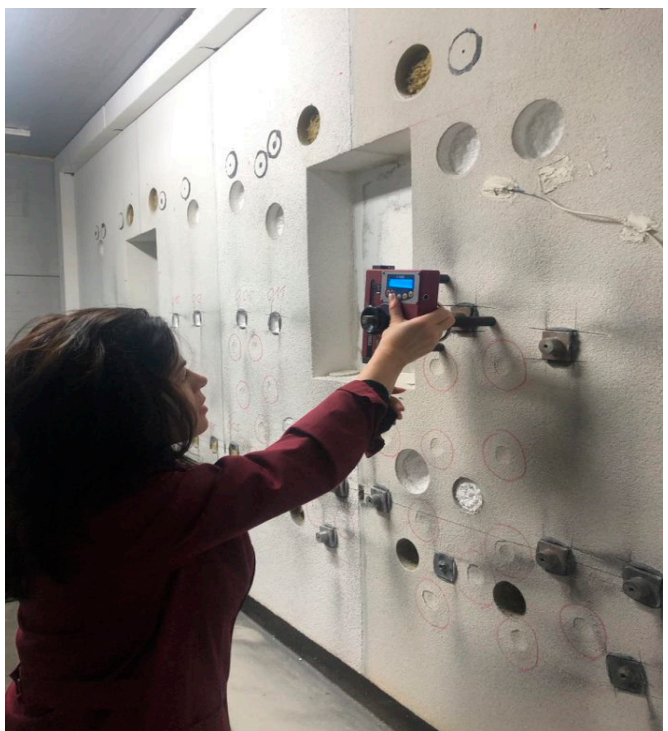

(a)

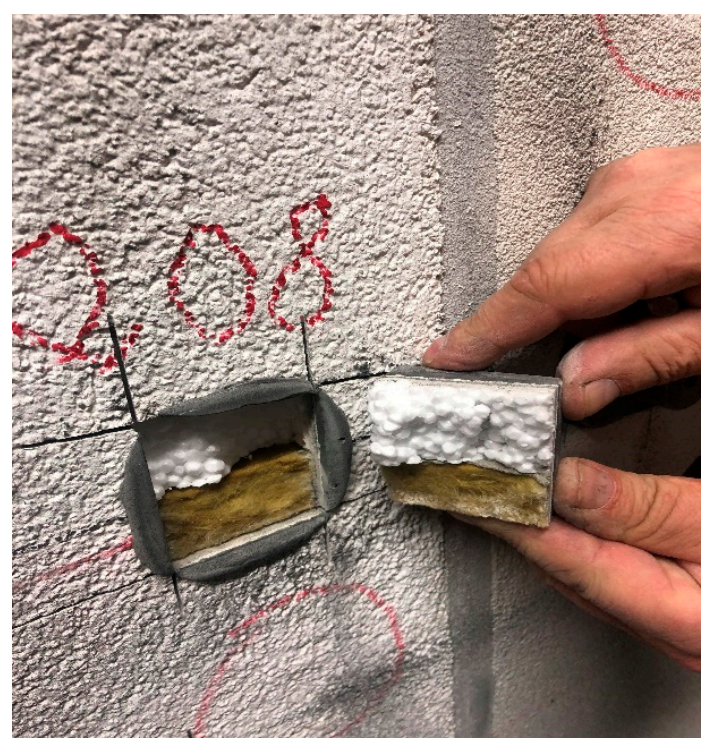

(b)

Figure 2. Testing of the bond strength of ETICS: (a) testing; (b) an example of the typical pull-off at the joint of EPS/MW.

\section{Results and Discussion}

From test results, none of the following defects occurred during and after the testing of ETIC systems:

- blistering or peeling of any finishing;

- failure or cracking associated with joints between insulation product boards;

- detachment of render;

- cracking allowing water penetration to the insulation layer.

Therefore, the above mentioned ETICS are deemed to be resistant to hydrothermal cycles. On the basis of the moisture testing results it can be seen that the amount of moisture content is different depending on both the type of plaster and the thermal insulation used. The measurement of mass humidity for individual types of plaster and thermal insulation after 80 heat-rain cycles in the case of EPS thermal insulation, the highest mass humidity was recorded for the ETICS with silicate plaster $(\mathrm{w}=2.3 \%)$. In the case of mineral wool, the highest value was obtained for silicate and acrylic plaster $(w=0.5 \%)$. This suggests the answers are critical with respect to their underlying mesh structures and its influence on ageing.

By analyzing the thermocouple data, the temperature difference across the whole depth of thermal insulation layers, and at the joints of the different layers during the hydrothermal cycle, changes in the same way, and does not depend on the type of thermal insulation layers (Figure 3).

The adhesion strength was about $0.11 \mathrm{MPa}$, at the points where pulling was performed from the polystyrene foam, in connections between polystyrene foam and mineral wool $-0.05 \mathrm{MPa}$ (Table 1). 


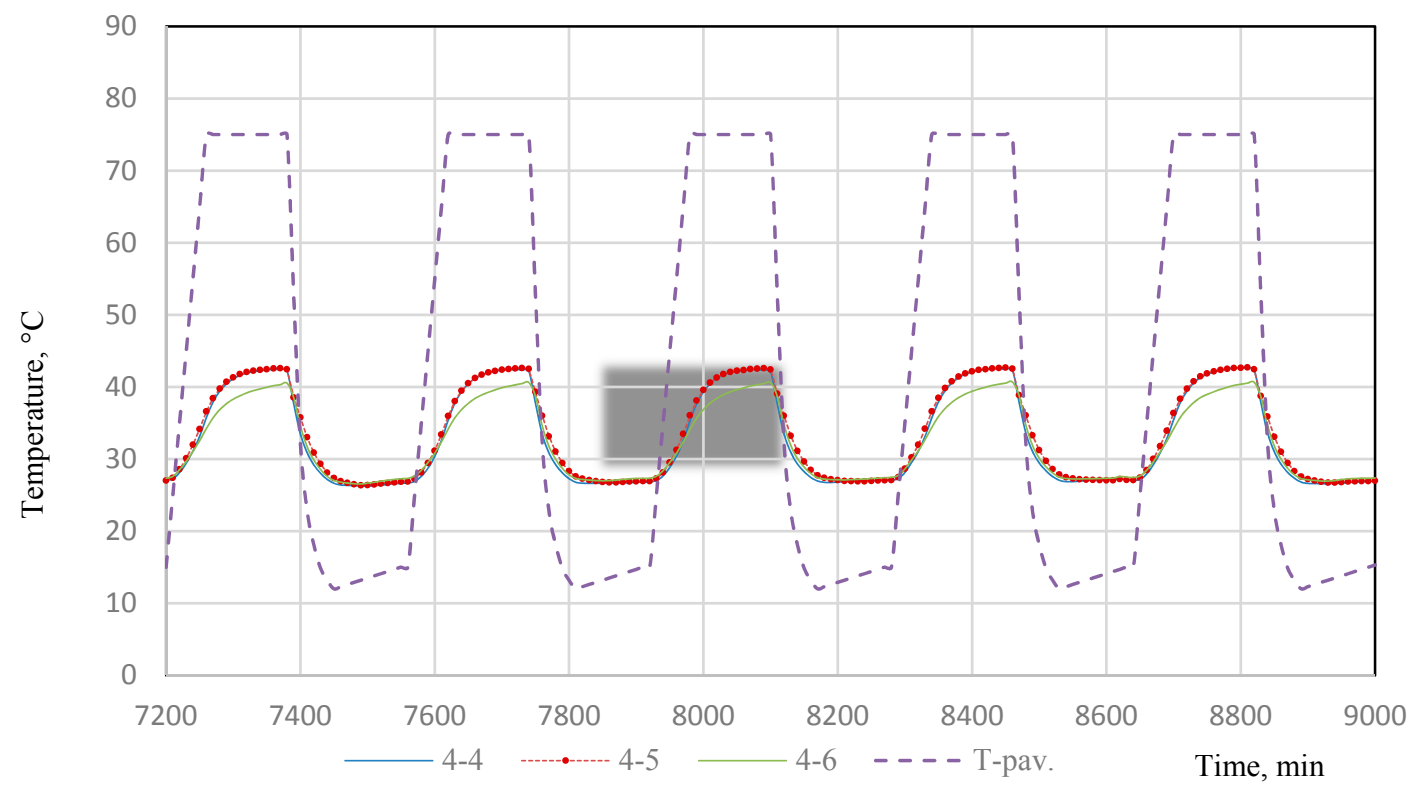

Figure 3. Temperature variation in ETICS fragment layers during hydrothermal cycles: 4-4 temperature in the middle of mineral wool, 4-5 temperature at the junction of mineral wool and polystyrene foam, 4-6 temperature in the middle of polystyrene foam. T-pav. - temperature on the rendering.

Table 1. Results of adhesion strength tests of mineral wool, EPS and joints between EPS and MW with base layer after hydrothermal cycles (touch-drying, cooling-heating).

\begin{tabular}{cccc}
\hline \multicolumn{4}{c}{ Adhesion Strength after Hydrothermal Cycles } \\
\hline System & Place & Average Value, MPa & Rupture Description \\
\hline \multirow{2}{*}{ ETICS No. 1 } & From EPS & 0.11 & cohesive \\
& At the joint EPS/MW & 0.05 & cohesive \\
\hline \multirow{2}{*}{ ETICS No. 2 } & From EPS & 0.11 & cohesive \\
& At the joint EPS/MW & 0.05 & cohesive \\
\hline \multirow{2}{*}{ ETICS No. 3 } & From EPS & 0.10 & cohesive \\
& At the joint EPS/MW & 0.05 & cohesive \\
\hline \multirow{2}{*}{ ETICS No. 4 } & From EPS & 0.10 & cohesive \\
& At the joint EPS/MW & 0.05 & cohesive \\
\hline
\end{tabular}

An analysis of the results of the impact resistance tests shows that the type and size of the damage show little influence from the type of heat-insulating material: EPS or MW, or the joints of these materials (MW/EPS). However, where thermal insulation material-mineral wool (MW) and two thermal insulation material connections (MW/EPS) - impacts on the ETICS samples, this caused less damage compared to impact where polystyrene foam only was used.

\section{Conclusions}

During and after the hydrothermal tests, no defects were found in the outer layer of the ETICS, (i.e., blistering and plastering in the outer layer, peeling or cracks in the joints of different types of insulation product panels or profiles). The absence of scratches, cracks, air bubbles and flaking of the external plaster layer indicates that, for the applied test procedure, there was no destruction of the complex external wall insulation system. This applies for EPS insulation with a layer of horizontal MW stripes located within the full wall and wall openings. The solutions adopted show resistance to the hydrothermal cycles assumed in the tests. The measurements of the temperature inside the wall and on its external surface do not cause significant differences in its distribution for different types of thermal insulation. 
The data obtained from these laboratory tests and analysis also meet practical needs for endusers. Although the initial results are found to be promising, it should be emphasized that further weathering tests are necessary in order to get a more reliable assessment on prediction of durability of ETICS. Further accelerated climatic tests are still ongoing in our scientific laboratory, with respective updated results to be published in due time.

Author Contributions: All authors contributed equally to this work. All authors discussed the results and commented on the manuscript at all stages. R.N. and A.B. prepared the methodology of hydrothermal behavior testing and performed the experiments; P.K. and K.M. analyzed the data and results. R.N. and V.B. wrote the paper. All authors have read and agreed to the published version of the manuscript.

Conflicts of Interest: The authors declare that there is no conflict of interest regarding the publication of this paper.

\section{References}

1. Daniotti, B.; Paolini, R. Evolution of degradation and decay in performance of ETICS. In Proceedings of the 11th International Conference on Durability of Building Materials and Components, Istanbul, Turkey, 11 May 2008; p. 42.

2. Gaciek, P.; Gaczek, M.; Garecki, M. Sposoby Mocowania Ociepleń do Powierzchni Ścian Wedlug Technologii ETICS; Warsaw, Poland 2018; Izolacje 10/2018.

3. Liismaa, E.; Sepria, R.; Raadob, L.-M.; Lillc, I.; Wittd, E.D.Q.; Sulakatkoc, V.; Põldarua, M. Defect analysis of renovated facade walls with etics solutions in cold climate conditions. In Proceedings of the Central Europe Towards Sustainable Building, Prague, Czech Republic, 22-24 June 2016

4. Pečur, I.B.; Bjegović, D.; Boström, L.; Milovanović, B. ETICS Fire Performance Test. In Proceedings of the Fifth International Workshop on Performance, Protection \& Strengthening of Structures Under Extreme Loading, At East Lansing, MI, USA, 28-30 June 2015. Available online: https://www.researchgate.net/publication/280385277_ETICS_Fire_Performance_Test (accessed on 15 December 2018).

5. Sulakatko, V.; Liisma, E.; Soekov, E. Increasing Construction Quality of External Thermal Insulation Composite System (ETICS) by revealing on-site degradation factors. Procedia Environ. Sci. 2017, 38, 765-772. doi:10.1016/j.proenv.2017.03.160.

6. Sulakatko, V.; Vogdt, F. Construction process technical impact factors on degradation of the external thermal insulation composite system. Sustainability 2018, 10, 3900, doi:10.3390/su10113900. Available online: https:/www.openaire.eu/search/publication?articleId=doajarticles::71bd2596e525ffed015fe1825443267f (accessed on 10 February 2020).

7. Barreira, E.; de Freitas, V.P. Experimental study of the hygrothermal behaviour of external thermal insulation composite systems (ETICS). Build. Environ. 2013, 63, 31-39, doi:10.1016/j.buildenv.2013.02.001.

8. Liisma, E.; Lõhmus, G.; Raado, L. The effect of temperature and humidity on the permanence of external thermal insulation composite systems. Procedia Eng. 2015, 108, 340-348, doi:10.1016/j.proeng.2015.06.156.

9. Šadauskienè, J.; Buska, A.; Ramanauskas, J.; Algimantas, V. Analysis of fire spread prevention measures in ETICS and their influence on durability. J. Sustain. Arch. Civ. Eng. 2016, 17, 33-44. Available online: https://www.ceeol.com/search/article-detail?id=570694 (accessed on 15 January 2020).

10. Steinbauer, V.; Kaufmann, J.; Zurbriggen, R.; Bühler, T.; Herwegh, M. Tracing hail stone impact on external thermal insulation composite systems (ETICS) - An evaluation of standard admission impact tests by means of high-speed-camera recordings. Int. J. Impact Eng. 2017, 109, 354-365, doi:10.1016/j.ijimpeng.2017.07.016. Available online: https://www.sciencedirect.com/science/article/pii/ S0734743X16309186 (accessed on 15 January 2020).

11. Barreira, E.; de Freitas, V.P. External thermal insulation composite systems: Critical parameters for surface hygrothermal behaviour. Adv. Mater. Sci. Eng. 2014, 2014, 1-16, doi:10.1155/2014/650752

12. Barreira, E.; de Freitas, V.P. Importance of thermography in the study of etics finishing coatings degradation due to algae and mildew growth. In Proceedings of the 10DBMC International Conference on Durability of Building Materials and Components, Lyon, France, 17-20 April 2005.

13. Mandilaras, I.; Atsonios, I.; Zannis, G.; Founti, M. Thermal performance of a building envelope incorporating ETICS with vacuum insulation panels and EPS. Energy Build. 2014, 85, 654-665. 
14. Kvande, T.; Bakken, N.; Bergheim, E.; Thue, J. Durability of ETICS with rendering in NorwayExperimental and field investigations. Buildings 2018, 8, 93, doi:10.3390/buildings8070093. Available online: https://search.proquest.com/docview/2125297481 (accessed on 21 January 2020).

15. Sulakatko, V.; Lilla, I.; Witta, E. Methodological framework to assess the significance of External Thermal Insulation Composite System (ETICS) on-site activities. Energy Procedia 2016, 96, 446-454.

16. Steidl, T.; Krause, P. Moisture transport in cellular concrete walls with the connector for thermal insulation. Periodica Polytech. Civ. Eng. 2018, 62, 986-991, doi:10.3311/PPci.11618.

17. Uygunoğlu, T.; Özgüven, S.; Çalış, M. Effect of plaster thickness on performance of external thermal insulation cladding systems (ETICS) in buildings. Constr. Build. Mater. 2016, 122, 496-504, doi:10.1016/j.conbuildmat.2016.06.128. Available online: https://www.sciencedirect.com/science/article/pii/ S0950061816310662 (accessed on 20 January 2020).

18. Norvaišienè, R.; Griciutè, G.; Bliūdžius, R.; Ramanauskas, J. The changes of moisture absorption properties during the service life of external thermal insulation composite system. Mater. Sci. 2013, 19, 103-107, doi:10.5755/j01.ms.19.1.3834. Available online: https://www.openaire.eu/search/publication?articleId= doajarticles::455354cd761fca8fcc5905c5acebc211 (accessed on 25 January 2020).

19. ETAG 004 Guideline for European Technical Approval of External Thermal Insulation Composite Systems with Rendering; European Organization for Technical Approvals: Brussels, Belgium, March 2013.

(C) 2020 by the authors. Licensee MDPI, Basel, Switzerland. This article is an open access article distributed under the terms and conditions of the Creative Commons Attribution (CC BY) license (http://creativecommons.org/licenses/by/4.0/). 